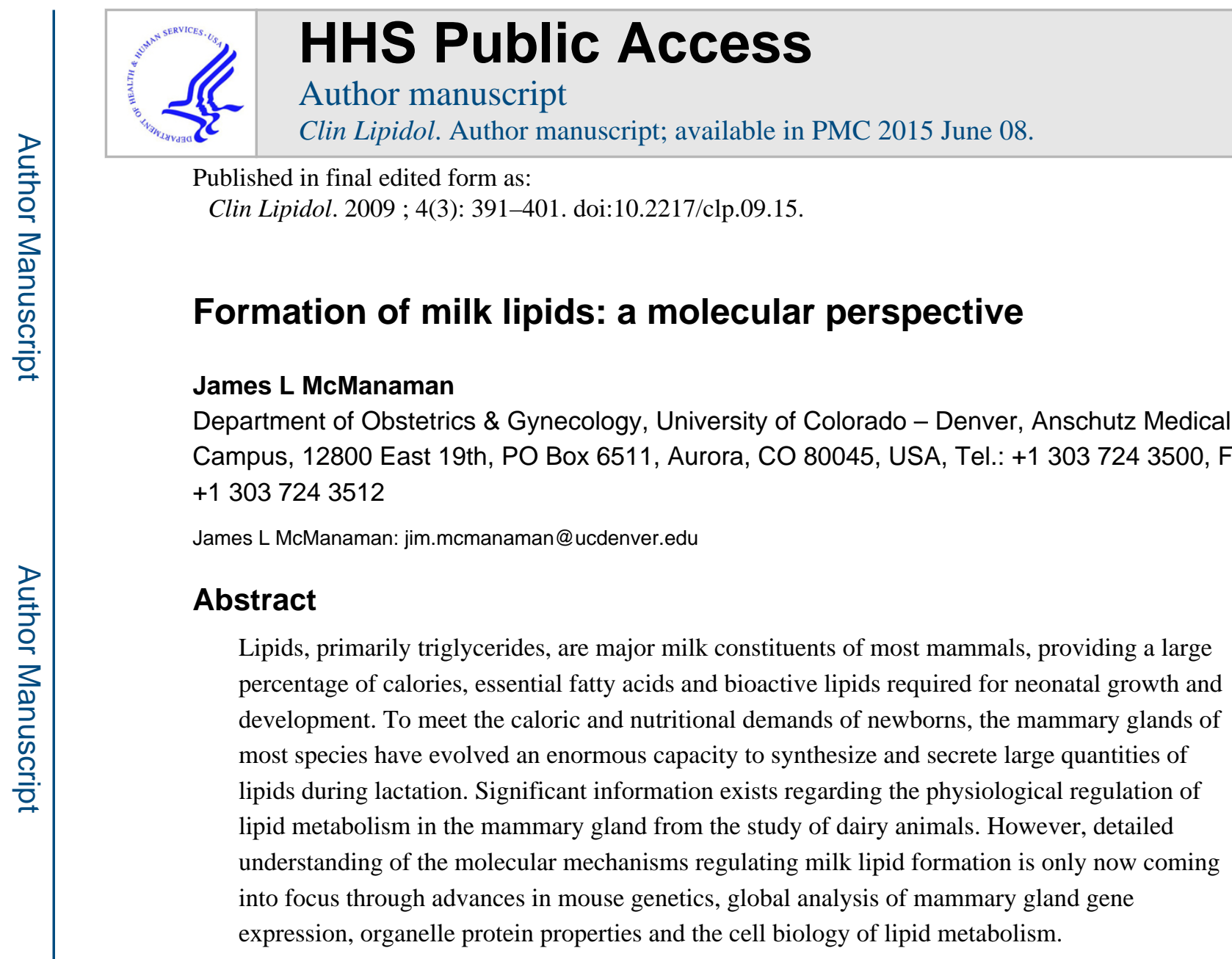

\title{
Keywords
}

1-acylglycerol-3-phosphate $O$-acyltransferase 6; adipophilin; cytoplasmic lipid droplet; diacylglycerol $O$-acyltransferase 1; lipogenesis; lipolysis; mammary gland differentiation; milk lipid; protein kinase-B; spot-14

\section{Importance of milk lipids}

The composition of milk has been tailored by evolution to meet the diverse neonatal growth and nutrient requirements of individual mammalian species. Owing to their high energy content, lipids in milk supply the majority of the calories required for neonatal growth in most species [1]. Milk lipids also provide a mechanism for transfer of fat-soluble vitamins to infants and are a primary source of essential fatty acids required for neonatal membrane synthesis and as substrates for synthesis of eicosanoids and other bioactive lipid signaling molecules [2]. In particular, long-chain polyunsaturated fatty acids (LC-PUFAs) such as arachidonic acid and docosahexaenoic acid, which are thought to be critical for early brain and retinal development of newborns, especially in preterm infants that have a reduced capacity to synthesize LC-PUFAs, are enriched in human breast milk [2]. Although adaptive

\section{(C) 2009 Future Medicine Ltd}

For reprint orders, please contact: reprints@ futuremedicine.com

Financial \& competing interests disclosure

The author has no other relevant affiliations or financial involvement with any organization or entity with a financial interest in or financial conflict with the subject matter or materials discussed in the manuscript apart from those disclosed. 
strategies exist, interference with milk lipid synthesis has been linked to neonatal growth restriction [3] and defects in newborn CNS and retinal development in humans and animal models [2].

\section{Milk lipid production}

The production of milk lipids makes significant demands on maternal metabolism; in humans and rodent models of lactation, the mammary gland is estimated to be one of the most active lipid-synthesizing and secreting organs in the body [4-6]. However, we currently know little regarding the energetics of milk lipid production or the specific mechanisms by which lipids are packaged and secreted into milk. Milk lipids are primarily composed of triglycerides (98\%) [7]. As first demonstrated by electron microscopy of lactating rat mammary glands [8], intracellular triglyceride droplets, known as cytoplasmic lipid droplets (CLDs), are secreted into milk as plasma membrane bilayer-coated structures (milk fat globules) by a process that is distinct from the classical secretory pathway used for lipid secretion by hepatocytes and enterocytes [9]. The sheer quantity of triglyceride synthesis during lactation, along with the novel mechanism by which it is secreted, make the mammary gland a physiologically useful system for investigating lipid metabolism in nonadipose cells as well as a unique model of lipid secretion.

\section{Secretory differentiation}

Milk is synthesized and secreted by specialized secretory epithelial cells that line the luminal cavity of mammary alveoli. The ability of these cells to synthesize and secrete milk is not a constitutive function but develops during pregnancy by a complex, hormonally driven, twostage secretory differentiation process $[10,11]$. The initial stage of secretory differentiation, which begins around mid-pregnancy in most species, is characterized by expansion of alveoli and induction of genes encoding milk proteins and enzymes responsible for synthesis of milk products. The second stage, initiated around the time of parturition by the fall in serum progesterone levels, is associated with further stimulation of biosynthetic processes and activation of mechanisms required for copious milk secretion [10]. Milk secretion is maintained during lactation, with production volume regulated by neonatal nutritional demands. Weaning results in inhibition of secretion, cessation of milk production, downregulation of milk synthesis genes and regression of alveoli to a prepregnancy state.

Accumulation of CLD in milk-secreting cells is one of the earliest histological features of the initial stage of secretory differentiation [12-14]. Observations that significant numbers of CLD are not present in epithelial cells lining ductal structures, or in myoepithelial cells surrounding alveoli, suggest that triglyceride accumulation in secretory epithelial cells is not simply the result of generalized alterations in lipid metabolism that occur during pregnancy [15]. Rather, the process appears to reflect activation of a specific differentiation program required for milk lipid production during lactation. Four histologically distinguishable phases of CLD accumulation have been identified in secretory epithelial cells in the mouse mammary gland (Figure 1). The initial phase is associated with formation of clusters of small CLDs $(<1 \mu \mathrm{m})$ in a limited number of immature alveoli beginning around midpregnancy [14]. CLD size and number then increase as alveoli expand and mature during the latter half of pregnancy (phases II and III), such that milk-secreting cells are completely 
filled with CLDs, many of which have diameters in excess of $10 \mu \mathrm{m}$, just prior to parturition (phase III) [14]. With the onset of milk secretion at parturition, CLDs dramatically decrease in size and move to the apical border as they begin to be secreted (phase IV) $[12,14]$. The pattern of CLD accumulation in differentiating milk-secreting cells suggests that milk lipid formation involves sequentially regulated lipogenic, transport and secretion phases that are functionally linked to the maturation of alveoli into milk-secreting structures.

\section{Milk lipid biogenesis}

Cytoplasmic lipid droplets, the immediate precursors of milk lipids, are composed of a hydrophobic core of neutral lipids (triacylglycerol [TAG] as well as cholesteryl and retinyl esters) that accounts for $90-95 \%$ of their mass. The core is surrounded by a phospholipid monolayer [16], representing 3-5\% of the CLD mass [17,18], and specific surfaceassociated proteins that are hypothesized to function in their formation, stabilization, trafficking and secretion [18-20]. Although only limited information exists regarding mechanisms of CLD biogenesis or the molecular machinery responsible for their assembly, evidence from studies of the mammary gland and other tissues have identified the endoplasmic reticulum (ER) as the likely site of their formation. Triglycerides and cholesteryl esters that form the neutral lipid core are synthesized by acyl-CoA:diacylglycerol acyltransferase (DGAT) and acyl-CoA:cholesterol acyltransferase enzymes, respectively, located in the ER [21-23]. The ability of the ER to directly incorporate newly synthesized TAG into CLD was originally demonstrated in the lactating mouse mammary gland by Stein and Stein [24]. Using electron microscopic radioautography they demonstrated that following tail vein injections of radioactive glycerol or oleic acid, the labeled molecules initially localized to ER cisternae and then rapidly accumulated in CLDs surrounded by ER membranes. More recently, Keenan et al. [25] and Marchasean et al. [26] demonstrated de novo generation of CLDs from isolated microsome fractions of mammary glands and cultured adipocytes, respectively.

\section{ER association}

Ultrastructural studies of rat liver [27], cultured mouse adipocytes [28,29], baby hamster kidney cells [30] and human monocytes [31,32] suggest that CLDs directly contact ER membranes. This concept is supported by biochemical studies identifying lumenal and integral membrane ER proteins on isolated CLD fractions from milk-secreting cells of lactating mammary glands by immunoblot [33] and 2D electrophoresis/mass spectrometry analyses [20]. The association of ER proteins with CLDs was subsequently confirmed in other cell types by proteomic analyses of CLDs from adipocytes [34], Chinese hamster ovary cells [35] and monocytes [32]. Evidence that milk lipids are directly derived from ERgenerated CLDs was obtained by Wu et al. [20], who showed that ER proteins found on CLDs isolated from milk-secreting cells were also present in the secreted milk fat globules (MFGs).

Despite convincing evidence that CLDs originate at the ER, the mechanism by which these structures form remains poorly understood and controversial. A widely accepted model is that newly synthesized TAG molecules accumulate between the ER membrane leaflets causing the membrane bilayer to swell, leading to the eventual release of TAG molecules as 
phospholipid monolayer-coated CLDs by a budding mechanism $[9,17,18,36]$. This model is based on observations of osmophilic distensions of the ER membrane bilayer in both plants and milk-secreting cells of lactating rats [9,37]. The observation of such distensions, however, appear to be rare occurrences $[18,38]$, indicating that TAG droplet accumulation between membrane leaflets is either a rapid transient event, in which little steady-state accumulation occurs, or that other mechanisms of CLD formation exist. Indeed, evidence exists that CLDs may originate in regions of the cytoplasm adjacent to specialized regions of the ER membrane [17,31].

\section{Triglyceride synthesis}

The glycerol and fatty acid substrates required for milk lipid synthesis are derived de novo from glucose, or obtained by transfer from the serum [39]. Coordinate increases in the activities of enzymes involved in de novo fatty acid synthesis [40,41] and transcript levels of genes encoding these enzymes $[42,43]$ have been documented in differentiating mammary glands of laboratory animals. Although the exact timing varies between species, induction of these enzymes occurs toward the end of pregnancy or at the beginning of lactation, with expression levels remaining elevated during lactation to maintain milk lipid production $[41,42]$. Correlating with increased expression of de novo fatty acid synthesis genes, there is a concomitant decrease in the expression of $\beta$-oxidation genes $[42,44]$. These changes occur in association with depletion of mammary adipose lipid $[45,46]$ and downregulation of adipose-specific genes involved in lipid metabolism and TAG storage [14,43]. While the cellular specificity and functional significance of these changes remain to be established, these findings suggest a model in which activation of lipogenic mechanisms in milksecreting cells is functionally integrated with inhibition of fatty acid oxidation and TAG storage in mammary adipose tissue in order to shunt glycerol and fatty acid substrates into the synthesis of milk lipids.

\section{De novo glycerol \& fatty acid synthesis}

Evidence of the importance of de novo glycerol and fatty acid synthesis to TAG formation and CLD accumulation comes from studies of transgenic mice in which protein kinase B (AKT1) was either overexpressed [5] or ablated [44]. AKT1-dependent signaling is known to influence the synthesis of glycerol and lipid from glucose by modulating glucose uptake $[5,44,47,48]$ and regulating the activity of ATP-citrate lyase, a key regulatory enzyme in de novo fatty acid synthesis [49,50]. Milk-secreting cells in AKT1-null mice exhibit normal morphology and milk protein expression but have impaired CLD accumulation, which correlates with decreased glucose uptake, reduced expression of fatty acid synthesis genes and elevated expression of $\beta$-oxidation genes [44]. Conversely, in transgenic mice overexpressing constitutively activated AKT1, there is precocious and pronounced accumulation of large CLDs in differentiating milk secreting cells and significant increases in the fat content of milk [5]. Collectively, these data argue for a central role for AKT1 in regulating TAG formation in milk-secreting cells by increasing de novo glycerol and fatty acid synthesis through: activation of glucose uptake; stimulation of biosynthetic enzyme expression; and inhibition of fatty acid oxidation [44]. These effects of AKT appear to be isozyme specific, as deficiencies in AKT-2 or -3 do not significantly affect mammary gland 
properties or milk lipid formation, despite altering the metabolic properties of other cell types [44].

In nonruminants, de novo fatty acid synthesis is responsible only for the production of medium-chain fatty acids (8-14 carbons) [39]. In addition to AKT1, medium-chain fatty acid synthesis in the mouse mammary gland appears to be regulated by Spot 14 (S14) [51]. S14 was identified in a screen of thyroid hormone-responsive genes in hepatic tissue [52]. Subsequently, deletion of the $S 14$ gene was found to inhibit medium-chain fatty acid production in mammary glands but not livers of lactating mice. The mechanism by which S14 regulates mammary gland fatty acid synthesis is not well understood but may involve regulation of fatty acid synthase activity, a key regulatory enzyme in the de novo synthesis of fatty acids in normal mammary tissue and mammary tumor cells [51,53,54]. Interestingly, preliminary reports indicate that $\mathrm{S} 14$ levels are increased in mammary glands of mice that express constitutively active AKT1 [6]. If correct, this observation suggests that regulation of S14 levels may be an additional mechanism by which AKT1 regulates milk lipid synthesis.

Long-chain fatty acids (16+ carbons) in milk lipids are obtained by transfer from the serum following lipoprotein lipase (LPL)-mediated release from serum triglycerides [39]. LPL transcript and activity levels in mouse mammary glands increase dramatically at the end of pregnancy [55] in conjunction with increased de novo fatty acid synthesis activities [6], suggesting the existence of physiological mechanisms for coordinately increasing the supply of both exogenously and de novo-derived fatty acids needed for milk lipid synthesis. Although hormonal actions have been implicated, the nature of the physiological mechanisms regulating de novo synthesis and exogenous uptake of fatty acids in the mammary gland remain poorly understood [6,39].

\section{Glycerol esterification}

Sequential fatty acid esterification of glycerol-3-phosphate [56] is the primary pathway of TAG synthesis in most cell types [57]. However, alternative pathways exist. In particular, formation of diacylglycerol by esterification of sn2-monoacylglycerol is a prominent pathway of TAG synthesis in intestinal epithelial cells, liver and adipose cells under certain conditions [57]. Detailed information concerning the pathway(s) involved in producing TAG for milk lipids is not available. However, recent studies have shown that mice deficient in Agpat6, a novel glycerol lipid acyltransferase family member, exhibit a lactation phenotype characterized by impaired milk production, reduced milk TAG levels and diminished numbers of CLDs in milk-secreting cells. These alterations appear to be specific to glandular elements, as mammary tissue of Agpat6-deficient mice retain lipid-rich adipocytes [58].

Although Agpat 6 contains glycerol lipid acyltransferase sequence motifs, it is only distantly related to other members of this family [58] and its enzymatic activity has not been established. These results raise the possibility that TAG synthesis in milk-secreting cells may occur by a unique Agpat 6-dependent pathway and further suggest that if alternative pathways are present, they are not sufficient to support CLD accumulation and milk lipid synthesis in the absence of Agpat6. 


\section{DGAT isozymes}

Two genetically different forms of DGAT (DGAT1, DGAT2) with distinct physiological functions have been identified in mammalian cells $[59,60]$. Ablation studies have documented that DGAT2 is responsible for the majority of triglyceride synthesis in mice and that animals born without this enzyme fail to survive owing to rapid dehydration resulting from skin barrier abnormalities [61]. On the other hand, DGAT1-deficient mice are viable and possess significant quantities of white adipose tissue (WAT) [62]. Nevertheless, these mice exhibit altered metabolic properties, defects in hair growth and fail to lactate [62]. Furthermore, histological and electromagnetic analyses of mammary glands of DGAT1-null mice documented impaired mammary gland development and the absence of CLD in milksecreting cells, despite the presence of adjacent lipid-rich WAT [62,63]. Using transplant studies, Cases et al. demonstrated distinct stromal and epithelial effects of DGAT1 loss on mammary gland development [63]. Wild-type epithelium transplanted into wild-type stroma developed into histologically normal glandular structures, whereas glandular development was impaired when wild-type epithelium was transplanted into the stroma of DGAT1-null mice. Conversely, when epithelium from DGAT1-null mice was transplanted into wild-type stroma, it developed into histologically normal glandular structures. However, milksecreting cells within these structures completely lacked CLD and exhibited evidence of impaired functional differentiation when compared with wild-type epithelium transplanted into wild-type stroma. These observations suggest DGAT1 in both the stromal and epithelial compartments is required for normal mammary gland development and that DGAT1 is specifically responsible for the synthesis of the TAG core of CLD in milk-secreting cells. The importance of DGAT1 in milk lipid production is further supported by genetic studies of cattle, which identified a nonconservative lysine to alanine substitution in DGAT1 that altered its enzymatic activity and was responsible for a quantitative trait locus affecting milk fat content [64].

\section{Triglyceride stabilization}

Proteins associated with the CLD surface play essential and specific roles in regulating TAG metabolism and CLD accumulation in all eukaryotic cells $[18,65,66]$. Such proteins include members of the perilipin (PAT) family of lipid-droplet associated proteins (perilipin, adipophilin, TIP47, S3-12 and lipid-storage droplet protein 5) [66,67]. A primary function of PAT proteins is thought to be to regulate TAG turnover by controlling lipase access to the TAG core of CLD [65,68-70]. Currently, perilipin and adipophilin are the only PAT proteins in which physiological roles in TAG accumulation have been established [71-74]. Other functions of PAT proteins in lipid metabolism, however, are possible. Adipophilin, for example, has been proposed to increase TAG accumulation by regulating fatty acid uptake [75], transferring lipid from the ER to the CLD [31], stimulating TAG biosynthesis [76] and inhibiting $\beta$-oxidation [76].

\section{Adipophilin is functionally linked to milk lipid formation}

The weight of the evidence to date suggests that adipophilin is the primary PAT protein associated with CLD in milk-secreting cells [14]. Adipophilin specifically localizes to CLD in these cells in both the bovine and mouse mammary gland [14,20,77,78]. In addition, 
adipophilin has been shown to colocalize with two proteins known to mediate milk lipid secretion, xanthine oxidoreductase (XOR) [79] and butyrophilin (BTN) [80], at sites of CLD secretion on the apical plasma membrane of lactating mice [81]. It is also a major protein constituent of secreted MFG in the milk of mice and cattle $[20,81,82]$, where it appears to exist in a detergent-stable, high-molecular weight complex with BTN and XOR $[81,82]$.

Although adipophilin mRNA is highly expressed in differentiated adipocytes [77,83], and elevated adipophilin levels are linked to lipid accumulation in many cell types $[66,77,84]$, in situ hybridization analysis of developing mouse mammary glands documented that adipophilin transcript levels in milk-secreting cells are markedly greater than those in surrounding cell types, including adipocytes [14]. Adipophilin expression in milk-secreting cells is induced approximately 30 -fold during secretory differentiation [14]. Its induction occurs around mid-pregnancy in conjunction with the initial appearance of CLD in milksecreting cells (phase I of accumulation), and several days before activation of lipid biosynthetic processes and major increases in CLD accumulation (phase III of accumulation) [14]. In mammary glands of lactating mice, microarray analysis indicates that adipophilin transcripts are among the most abundant present, being equivalent to that of other secreted milk proteins, such as the caseins [42]. Collectively, these results suggest that high-level adipophilin expression is a specialized property of differentiated milk-secreting cells that has been adapted for the production of milk lipids during lactation $[9,14]$.

However, understanding the precise physiological role that adipophilin plays in milk lipid formation has been complicated by the discovery that mammary glands of mice thought to be adipophilin-null synthesize an N-terminally truncated form of adipophilin [85]. The adiphphilin gene $(A D F P)$ is composed of eight exons, with the initiating methionine located in exon 2 [67]. In the putative adipophilin-null mice, exons 2 and 3 were replaced by a Geo cassette, leaving regulatory elements, exon 1 and exons 4-8 intact [73]. Initial characterization of adipophilin-null mice failed to detect any adipophilin protein or mRNA in their livers, suggesting complete disruption of $A D F P$ gene expression. However, QRTPCR analysis subsequently showed that lactating mammary glands of these adipophilin-null mice expressed transcripts corresponding to exons 4-8 of adipophilin and immunoblots and immunolocalization studies using C-terminal-specific antibodies documented that they possessed a lower-molecular weight form of adipophilin that specifically localized to CLD and secreted MFG [85]. Although the exact mechanism by which the N-terminally truncated form of adipophilin is produced from exons $4-8$ has not been established, it appears to be generated from an internal translation initiation site located in exon 5 [85].

The observation that the N-terminally truncated form of adipophilin found in adipophilinnull mice localizes to CLD is consistent with earlier cell culture experiments showing that loss of the N-terminal region of adipophilin does not interfere with its ability to bind CLD $[86,87]$. These findings suggest the possibility that the truncated molecule retains the ability to mediate formation and secretion of milk lipids. Indeed, mammary glands of adipophilinnull mice expressing the truncated form of adipophilin are capable of synthesizing and secreting milk lipids, albeit at lower levels than wild-type animals [85]. 


\section{Perilipin \& TIP47}

Perilipin and TIP47 are also present in mammary tissue; however, they do not appear to be associated with milk lipids under normal conditions. Perilipin specifically localizes to small pockets of adipose tissue present in mammary glands of lactating mice [14]. On the other hand, TIP47 is found in milk-secreting cells, but it specifically localizes to diffusely distributed punctate structures rather than CLDs [14]. In mouse milk TIP47 immunoreactivity is detected in the fat-depleted (skim milk) fraction but not in the MFG fraction [14]. The expression properties of TIP47 are also not consistent with it being an actively secreted protein. QRT-PCR analysis of developing mouse mammary glands showed that its transcript levels were only a fraction of those of adipophilin; and unlike transcript levels of secreted proteins, those of TIP47 decreased over the course of secretory differentiation and lactation [14]. Nevertheless, TIP47 has been detected on MFG from human milk $[88,89]$, raising the possibility that it is somehow involved in milk lipid secretion. However, the functional significance of this association has been questioned $[14,89]$, and it is possible that TIP47 becomes associated with MFG during membrane envelopment of CLDs, which in some species - including humans - results in the inclusion of significant amounts of cytoplasm along with vesicular structures [12,14]. TIP47, however, does localize to CLD in milk-secreting cells of adipophilin-null mice [85] and it may function to increase TAG accumulation under conditions of adipophilin deficiency $[69,85]$. However, its exact function in this process remains uncertain as it does not appear to interfere with lipase association to CLD [70].

\section{Conclusion}

The capacity of milk-secreting cells to synthesize and secrete large quantities of lipids required for neonatal growth and development is induced during the differentiation of the mammary gland into a secretory organ. Comparison of the time courses of induction of adipophilin and lipid biosynthesis genes to the histological phases of CLD accumulation suggest a bipartite model of milk lipid biogenesis, in which the synthesis of adipophilin and perhaps that of other molecules required for stabilizing triglyceride droplets are induced prior to processes that stimulate TAG synthesis. In this model, modest increases in CLD accumulation occurring during the initial phases of differentiation are proposed to reflect primarily adipophilin-dependent inhibition of TAG lipolysis; whereas the major increases in CLD accumulation that occur toward the end of differentiation are due to dramatic increases in DGAT1-dependent TAG synthesis (Figure 2). Increased TAG synthesis appears to be regulated by coordinate activation of mechanisms that increase the availability of fatty acid and glycerol substrates. These mechanisms involve AKT-1-dependent activation of de novo fatty acid and glycerol synthesis, LPL-dependent uptake of fatty acids from exogenous sources and decreased fatty acid oxidation.

\section{Future perspective}

Because lipids are a substantial component of the milk of most mammals, and the lipogenic mechanisms in milk-secreting cells are developmentally regulated, the mammary gland provides a sensitive and accessible physiological model to investigate fundamental 
mechanisms of milk lipid biogenesis and secretion. There are several pressing questions related to these mechanisms:

What regulates CLD biogenesis and what is the role of the ER membrane in this process? The hypothesis that CLDs originate by accumulation of triglyceride between ER membrane leaflets is mechanistically attractive since it provides a viable explanation for the origins of the phospholipid monolayer and the proteins associated with the CLD surface. However, there is little direct support for this mechanism, and essentially nothing is known about the molecular properties of synthesis sites or the mechanics of CLD assembly. Moreover, if CLDs are intimately associated with the ER, it is unclear how they are transported to the apical membrane for secretion?

What regulates CLD size? There is an enormous variability in CLD size within eukaryotic cells and little is known regarding how CLD size is controlled in any cell type. At the physiological level, the size of CLDs in milk-secreting cells appears to reflect the balance between their biogenesis, lipolysis and secretion rates. However, it is unclear whether CLDs grow by fusion of smaller CLDs with one another, by accretion of triglycerides within existing CLDs, by increasing triglyceride incorporation into the CLD core at the time of their assembly, or by limiting lipolysis of their triglyceride core. Consequently, understanding CLD growth mechanisms will require knowledge of both biogenesis and lipolysis mechanisms;

- What controls CLD accumulation during differentiation of milk-secreting cells? Although the enzymatic pathways controlling fatty acid and triglyceride synthesis are known, the contributions of individual components of these pathways to CLD accumulation is poorly understood. Conversely, we know very little regarding the role of lipolysis in CLD accumulation. Importantly, the identity of lipases that mediate this triglyceride hydrolysis and the contributions of specific CLD-associated proteins, such as adipophilin, to the control of lipolytic activity in milk-secreting cells remain undefined;
What is the mechanism of milk lipid secretion? Milk lipid secretion is a multiple step process requiring directional transport of CLDs from their sites of synthesis on the ER membrane to the apical plasma membrane, interaction of CLDs with apical plasma membrane components to initiate membrane envelopment and release of membrane-enveloped CLDs into milk. Other than identifying XOR and BTN as essential for milk lipid secretion, we know few details concerning any aspect of this process. Observations that adipophilin colocalizes with XOR and BTN at sites of CLD secretion on the apical membrane, and that it forms stable complexes with XOR and BTN in secreted MFG, implicate interactions between these three proteins in the secretion mechanism. However, additional studies are needed to verify the involvement of adipophilin in the secretion process and to define the specific contributions of each of these proteins to the mechanism of secretion. 


\section{Acknowledgments}

The author wishes to thank S Anderson, D Dehn, P Neville and D Orlicky for helpful discussions.

This work was supported by NIH grants RO1HD045962, PO1HD38129 and R21HD050863.

No writing assistance was utilized in the production of this manuscript.

\section{Bibliography}

Papers of special note have been highlighted as:

- of interest

1. Oftedal OT. Use of maternal reserves as a lactation strategy in large mammals. Proc Nutr Soc. 2000; 59:99-106. [PubMed: 10828179]

2. Koletzko B, Rodriguez-Palmero M. Polyunsaturated fatty acids in human milk and their role in early infant development. J Mammary Gland Biol Neoplasia. 1999; 4:269-284. [PubMed: 10527469]

3. Ringseis R, Saal D, Muller A, Steinhart H, Eder K. Dietary conjugated linoleic acids lower the triacylglycerol concentration in the milk of lactating rats and impair the growth and increase the mortality of their suckling pups. J Nutr. 2004; 134:3327-3334. [PubMed: 15570033]

4. Allen JC, Keller RP, Archer PC, Neville MC. Studies in human lactation: 6. Milk composition and daily secretion rates of macronutrients in the first year of lactation. Am J Clin Nutr. 1991; 54:69-80. [PubMed: 2058590]

5. Schwertfeger KL, McManaman JL, Palmer CA, Neville MC, Anderson SM. Expression of constitutively activated Akt in the mammary gland leads to excess lipid synthesis during pregnancy and lactation. J Lipid Res. 2003; 44:1100-1112. [PubMed: 12700340]

6. Rudolph MC, Neville MC, Anderson SM. Lipid synthesis in lactation: diet and the fatty acid switch. J Mammary Gland Biol Neoplasia. 2007; 12:269-281. [PubMed: 18027074]

7. Dils, R.; Clark, S.; Knudsen, J. Comparative aspects of milk fat synthesis. In: Peaker, M., editor. Comparative Aspects of Lactation. Academic Press; London, UK: 1977. p. 43-55.

8. Bargmann W, Knoop A. Morphology of lactation; light \& electro-microscopic studies on the mammary glands of rats. Z Zellforsch Mikrosk Anat. 1959; 49:344-388. [PubMed: 13648715]

9. Mather IH, Keenan TW. Origin and secretion of milk lipids. J Mammary Gland Biol Neoplasia. 1998; 3:259-273. Good overall review of milk lipid formation and secretion mechanisms. [PubMed: 10819513]

10. Neville MC, McFadden TB, Forsyth I. Hormonal regulation of mammary differentiation and milk secretion. J Mammary Gland Biol Neoplasia. 2002; 7:49-66. [PubMed: 12160086]

11. Brisken C. Hormonal control of alveolar development its implications for breast carcinogenesis. J Mammary Gland Biol Neoplasia. 2002; 7(1):39-48. [PubMed: 12160085]

12. Hollmann, KH. Cytology fine structure of the mammary gland. In: Larson, BL.; Smith, VR., editors. Lactation. Vol. 1. Academic Press; NY, USA: 1974. p. 3-95.

13. Wooding, FB. P. Comparative mammary fine structure. In: Peaker, M., editor. Comparative Aspects of Lactation. Academic Press; London, UK: 1977. p. 1-41.

14匹. Russell TD, Palmer CA, Orlicky DJ, et al. Cytoplasmic lipid droplet accumulation in developing mammary epithelial cells: roles of adipophilin lipid metabolism. J Lipid Res. 2007; 48:14631475. Developmental regulation of adipophilin cytoplasmic lipid droplet (CLD) accumulation in the mouse mammary gland. [PubMed: 17452747]

15. Herrera E. Lipid metabolism in pregnancy its consequences in the fetus newborn. Endocrine. 2002; 19:43-55. [PubMed: 12583601]

16. Tauchi-Sato K, Ozeki S, Houjou T, Taguchi R, Fujimoto T. The surface of lipid droplets is a phospholipid monolayer with a unique fatty acid composition. J Biol Chem. 2002; 277:4450744512. [PubMed: 12221100]

17. Zweytick D, Athenstaedt K, Daum G. Intracellular lipid particles of eukaryotic cells. Biochim Biophys Acta. 2000; 1469:101-120. [PubMed: 10998572] 
18. Murphy DJ. The biogenesis functions of lipid bodies in animals, plants microorganisms. Prog Lipid Res. 2001; 40:325-438. Comprehensive review of intracellular lipid droplet formation functions. [PubMed: 11470496]

19. Londos C, Brasaemle DL, Schultz CJ, Segrest JP, Kimmel AR. Perilipins, ADRP, other proteins that associate with intracellular neutral lipid droplets in animal cells. Semin Cell Dev Biol. 1999; 10:51-58. [PubMed: 10355028]

20匹. Wu CC, Howell KE, Neville MC, Yates JR 3rd, McManaman JL. Proteomics reveal a link between the endoplasmic reticulum lipid secretory mechanisms in mammary epithelial cells. Electrophoresis. 2000; 21:3470-3482. First proteomic analysis of CLDs. [PubMed: 11079566]

21. Weiss SB, Kennedy EP, Kiyasu JY. The enzymatic synthesis of triglycerides. J Biol Chem. 1960; 235:40-44. [PubMed: 13843753]

22. Yen CL, Stone SJ, Koliwad S, Harris C, Farese RV Jr. Thematic review series: glycerolipids. DGAT enzymes triacylglycerol biosynthesis. J Lipid Res. 2008; 49:2283-2301. [PubMed: 18757836]

23. Suckling KE, Stange EF. Role of acyl-CoA: cholesterol acyltransferase in cellular cholesterol metabolism. J Lipid Res. 1985; 26:647-671. [PubMed: 3897424]

24. Stein O, Stein Y. Lipid synthesis, intracellular transport, secretion. II. Electron microscopic radioautographic study of the mouse lactating mammary gland. J Cell Biol. 1967; 34:251-263. [PubMed: 6033535]

25. Keenan TW, Dylewski DP, Ghosal D, Keon BH. Milk lipid globule precursor release from endoplasmic reticulum reconstituted in a cell-free system. Eur J Cell Biol. 1992; 57:21-29. [PubMed: 1639090]

26. Marchesan D, Rutberg M, Andersson L, et al. A phospholipase D-dependent process forms lipid droplets containing caveolin, adipocyte differentiation-related protein, vimentin in a cell-free system. J Biol Chem. 2003; 278:27293-27300. [PubMed: 12730229]

27. Stein O, Stein Y. Lipid synthesis, intracellular transport, storage, secretion. I. Electron microscopic radioautographic study of liver after injection of tritiated palmitate or glycerol in fasted ethanoltreated rats. J Cell Biol. 1967; 33:319-339. [PubMed: 6039375]

28. Novikoff AB, Novikoff PM, Rosen OM, Rubin CS. Organelle relationships in cultured 3T3-L1 preadipocytes. J Cell Biol. 1980; 87:180-196. [PubMed: 7191426]

29. Blanchette-Mackie EJ, Dwyer NK, Barber T, et al. Perilipin is located on the surface layer of intracellular lipid droplets in adipocytes. J Lipid Res. 1995; 36:1211-1226. [PubMed: 7665999]

30. Pol A, Luetterforst R, Lindsay M, et al. A caveolin dominant negative mutant associates with lipid bodies induces intracellular cholesterol imbalance. J Cell Biol. 2001; 152:1057-1070. [PubMed: 11238460]

31. Robenek H, Hofnagel O, Buers I, et al. Adipophilin-enriched domains in the ER membrane are sites of lipid droplet biogenesis. J Cell Sci. 2006; 119:4215-4224. Alternative mechanism of CLD biogenesis. [PubMed: 16984971]

32. Wan HC, Melo RC, Jin Z, Dvorak AM, Weller PF. Roles origins of leukocyte lipid bodies: proteomic ultrastructural studies. FASEB J. 2007; 21:167-178. [PubMed: 17135363]

33. Ghosal D, Shappell NW, Keenan TW. Endoplasmic reticulum lumenal proteins of rat mammary gland. Potential involvement in lipid droplet assembly during lactation. Biochim Biophys Acta. 1994; 1200:175-181. [PubMed: 8031838]

34. Brasaemle DL, Dolios G, Shapiro L, Wang R. Proteomic analysis of proteins associated with lipid droplets of basal lipolytically stimulated 3T3-L1 adipocytes. J Biol Chem. 2004; 279:4683546842. [PubMed: 15337753]

35. Liu P, Ying Y, Zhao Y, et al. Chinese hamster ovary K2 cell lipid droplets appear to be metabolic organelles involved in membrane traffic. J Biol Chem. 2004; 279:3787-3792. [PubMed: 14597625]

36. Brown DA. Lipid droplets: proteins floating on a pool of fat. Curr Biol. 2001; 11:R446-R449. [PubMed: 11516669]

37. Zaczek M, Keenan TS. Morphological evidence for an endoplasmic reticulum origin of milk lipid globules obtained using lipid-selective staining procedures. Protoplasma. 1990; 159:179-182. 
38. McManaman JL, Reyland ME, Thrower EC. Secretion fluid transport mechanisms in the mammary gland: comparisons with the exocrine pancreas the salivary gland. J Mammary Gland Biol Neoplasia. 2006; 11:249-268. [PubMed: 17136613]

39. Neville MC, Picciano MF. Regulation of milk lipid synthesis composition. Annu Rev Nutr. 1997; 17:159-184. [PubMed: 9240924]

40. Baldwin, RL.; Yang, YT. Enzymatic metabolic changes in the development of lactation. In: Larson, BL.; Smith, VR., editors. Lactation. Academic Press; NY, USA: 1974. p. 349-407.

41. Mellenberger RW, Bauman DE. Metabolic adaptations during lactogenesis. Fatty acid synthesis in rabbit mammary tissue during pregnancy lactation. Biochem J. 1974; 138:373-379. [PubMed: 4154742]

42. Rudolph MC, McManaman JL, Hunter L, Phang T, Neville MC. Functional development of the mammary gland: use of expression profiling trajectory clustering to reveal changes in gene expression during pregnancy, lactation, involution. J Mammary Gland Biol Neoplasia. 2003; 8:287-307. Array analysis of gene expression in the mouse mammary gland during secretory activation. [PubMed: 14973374]

43. Rudolph MC, McManaman JL, Phang T, et al. Metabolic regulation in the lactating mammary gland: a lipid synthesizing machine. Physiol Genomics. 2007; 28:323-336. [PubMed: 17105756]

44⿴. Boxer RB, Stairs DB, Dugan KD, et al. Isoform-specific requirement for Akt1 in the developmental regulation of cellular metabolism during lactation. Cell Metab. 2006; 4:475-490. Evidence of AKT-1 requirement for triacylglycerol (TAG) synthesis in the mouse mammary gland. [PubMed: 17141631]

45. Elias JJ, Pitelka DR, Armstrong RC. Changes in fat cell morphology during lactation in the mouse. Anat Rec. 1973; 177:533-547. [PubMed: 4762729]

46. Neville MC, Medina D, Monks J, Hovey RC. The mammary fat pad. J Mammary Gland Biol Neoplasia. 1998; 3:109-116. [PubMed: 10819521]

47. Kohn AD, Summers SA, Birnbaum MJ, Roth RA. Expression of a constitutively active Akt Ser/Thr kinase in 3T3-L1 adipocytes stimulates glucose uptake glucose transporter 4 translocation. J Biol Chem. 1996; 271:31372-31378. [PubMed: 8940145]

48. Magun R, Burgering BM, Coffer PJ, et al. Expression of a constitutively activated form of protein kinase B (c-Akt) in 3T3-L1 preadipose cells causes spontaneous differentiation. Endocrinology. 1996; 137:3590-3593. [PubMed: 8754791]

49. Berwick DC, Hers I, Heesom KJ, Moule SK, Tavare JM. The identification of ATP-citrate lyase as a protein kinase B (Akt) substrate in primary adipocytes. J Biol Chem. 2002; 277:33895-33900. [PubMed: 12107176]

50. Bauer DE, Hatzivassiliou G, Zhao F, Andreadis C, Thompson CB. ATP citrate lyase is an important component of cell growth transformation. Oncogene. 2005; 24:6314-6322. [PubMed: 16007201]

51 . LaFave LT, Augustin LB, Mariash CN. S14: insights from knockout mice. Endocrinology. 2006; 147:4044-4047. Evidence for the importance of Spot 14 in the regulation of fatty acid synthesis in the mammary gland. [PubMed: 16809440]

52. Seelig S, Liaw C, Towle HC, Oppenheimer JH. Thyroid hormone attenuates and augments hepatic gene expression at a pretranslational level. Proc Natl Acad Sci USA. 1981; 78:4733-4737. [PubMed: 6946422]

53. Wright TC, Cant JP, Brenna JT, McBride BW. Acetyl CoA carboxylase shares control of fatty acid synthesis with fatty acid synthase in bovine mammary homogenate. J Dairy Sci. 2006; 89:25522558. [PubMed: 16772574]

54. Knowles LM, Smith JW. Genome-wide changes accompanying knockdown of fatty acid synthase in breast cancer. BMC Genomics. 2007; 8:168. [PubMed: 17565694]

55. Jensen DR, Gavigan S, Sawicki V, Witsell D, Eckel RH, Neville MC. Regulation of lipoprotein lipase activity in the mammary gland of the lactating mouse. Biochem J. 1994; 298:321-327. [PubMed: 8135737]

56. Kennedy EP. Metabolism of lipides. Annu Rev Biochem. 1957; 26:119-148. [PubMed: 13488391]

57. Coleman RA, Lee DP. Enzymes of triacylglycerol synthesis their regulation. Prog Lipid Res. 2004; 43:134-176. [PubMed: 14654091] 
58. Beigneux AP, Vergnes L, Qiao X, et al. Agpat6 - a novel lipid biosynthetic gene required for triacylglycerol production in mammary epithelium. J Lipid Res. 2006; 47:734-744. Functional importance of Agpat6 in TAG synthesis in the mammary gland. [PubMed: 16449762]

59. Cases S, Stone SJ, Zhou P, et al. Cloning of DGAT2, a second mammalian diacylglycerol acyltransferase, related family members. J Biol Chem. 2001; 276:38870-38876. [PubMed: 11481335]

60. Cases S, Smith SJ, Zheng YW, et al. Identification of a gene encoding an acyl CoA:diacylglycerol acyltransferase, a key enzyme in triacylglycerol synthesis. Proc Natl Acad Sci USA. 1998; 95:13018-13023. [PubMed: 9789033]

61. Stone SJ, Myers HM, Watkins SM, et al. Development of the mammary gland requires DGAT1 expression in stromal epithelial tissues. Development. 2004; 131:3047-3055. [PubMed: 15163627]

62. Smith SJ, Cases S, Jensen DR, et al. Obesity resistance and multiple mechanisms of triglyceride synthesis in mice lacking. DGAT. 2000; 25:87-90.

63 . Cases S, Zhou P, Shillingford JM, et al. Development of the mammary gland requires DGAT1 expression in stromal and epithelial tissues. Development. 2004; 131:3047-3055. Demonstration of the importance of DGAT1 to mammary gland development. [PubMed: 15163627]

64. Grisart B, Farnir F, Karim L, et al. Genetic functional confirmation of the causality of the DGAT1 K232A quantitative trait nucleotide in affecting milk yield composition. Proc Natl Acad Sci USA. 2004; 101:2398-2403. [PubMed: 14983021]

65. Wolins NE, Brasaemle DL, Bickel PE. A proposed model of fat packaging by exchangeable lipid droplet proteins. FEBS Lett. 2006; 580:5484-5491. [PubMed: 16962104]

66. Ducharme NA, Bickel PE. Lipid droplets in lipogenesis lipolysis. Endocrinology. 2008; 149:942949. [PubMed: 18202123]

67. Lu X, Gruia-Gray J, Copeland NG, et al. The murine perilipin gene: the lipid droplet-associated perilipins derive from tissue-specific, mRNA splice variants and define a gene family of ancient origin. Mamm Genome. 2001; 12:741-749. Description of the PAT gene family. [PubMed: 11641724]

68. Londos C, Sztalryd C, Tansey JT, Kimmel AR. Role of PAT proteins in lipid metabolism. Biochimie. 2005; 87:45-49. [PubMed: 15733736]

69. Sztalryd C, Bell M, Lu X, et al. Functional compensation for adipose differentiation-related protein (ADFP) by TIP47 in an ADFP null embryonic cell line. J Biol Chem. 2006; 281:34341-34348. [PubMed: 16968708]

70匹. Listenberger LL, Ostermeyer-Fay AG, Goldberg EB, Brown WJ, Brown DA. Adipocyte differentiation-related protein reduces lipid droplet association of adipose triglyceride lipase and slows triacylglycerol turnover. J Lipid Res. 2007; 48:2751-2761. Demonstration that adipophilin controls access of ATGL to the CLD core. [PubMed: 17872589]

71. Tansey JT, Sztalryd C, Gruia-Gray J, et al. Perilipin ablation results in a lean mouse with aberrant adipocyte lipolysis, enhanced leptin production, resistance to diet-induced obesity. Proc Natl Acad Sci USA. 2001; 98:6494-6499. [PubMed: 11371650]

72. Martinez-Botas J, Anderson JB, Tessier D, et al. Absence of perilipin results in leanness reverses obesity in Lepr $(d b / d b)$ mice. Nat Genet. 2000; 26:474-479. [PubMed: 11101849]

73 . Chang BH, Li L, Paul A, et al. Protection against fatty liver but normal adipogenesis in mice lacking adipose differentiation-related protein. Mol Cell Biol. 2006; 26:1063-1076.

Physiological evidence that adipophilin is required for CLD accumulation. [PubMed: 16428458]

74. Imai Y, Varela GM, Jackson MB, et al. Reduction of hepatosteatosis lipid levels by an adipose differentiation-related protein antisense oligonucleotide. Gastroenterology. 2007; 132:1947-1954. [PubMed: 17484887]

75. Gao J, Serrero G. Adipose differentiation related protein (ADRP) expressed in transfected COS-7 cells selectively stimulates long chain fatty acid uptake. J Biol Chem. 1999; 274:16825-16830. [PubMed: 10358026]

76. Larigauderie G, Cuaz-Perolin C, Younes AB, et al. Adipophilin increases triglyceride storage in human macrophages by stimulation of biosynthesis inhibition of $\beta$-oxidation. FEBS J. 2006; 273:3498-3510. [PubMed: 16884492] 
77. Brasaemle DL, Barber T, Wolins NE, Serrero G, Blanchette-Mackie EJ, Londos C. Adipose differentiation-related protein is an ubiquitously expressed lipid storage droplet-associated protein. J Lipid Res. 1997; 38:2249-2263. [PubMed: 9392423]

78. Heid HW, Moll R, Schwetlick I, Rackwitz HR, Keenan TW. Adipophilin is a specific marker of lipid accumulation in diverse cell types diseases. Cell Tissue Res. 1998; 294:309-321. [PubMed: 9799447]

79. Vorbach C, Scriven A, Capecchi MR. The housekeeping gene xanthine oxidoreductase is necessary for milk fat droplet enveloping secretion: gene sharing in the lactating mammary gland. Genes Dev. 2002; 16:3223-3235. [PubMed: 12502743]

80. Ogg SL, Weldon AK, Dobbie L, Smith AJ, Mather IH. Expression of butyrophilin (Btn1a1) in lactating mammary gland is essential for the regulated secretion of milk-lipid droplets. Proc Natl Acad Sci USA. 2004; 101:10084-10089. [PubMed: 15226505]

81. McManaman JL, Palmer CA, Wright RM, Neville MC. Functional regulation of xanthine oxidoreductase expression localization in the mouse mammary gland: evidence of a role in lipid secretion. J Physiol. 2002; 545:567-579. [PubMed: 12456835]

82. Heid HW, Schnolzer M, Keenan TW. Adipocyte differentiation-related protein is secreted into milk as a constituent of milk lipid globule membrane. Biochem J. 1996; 320(Pt 3):1025-1030. [PubMed: 9003395]

83. Jiang HP, Serrero G. Isolation characterization of a full-length cDNA coding for an adipose differentiation-related protein. Proc Natl Acad Sci USA. 1992; 89:7856-7860. [PubMed: 1518805]

84. Londos C, Brasaemle DL, Schultz CJ, Segrest JP, Kimmel AR. Perilipins, ADRP, other proteins that associate with intracellular neutral lipid droplets in animal cells. Semin Cell Dev Biol. 1999; 10:51-58. [PubMed: 10355028]

85 . Russell TD, Palmer CA, Orlicky DJ, et al. Mammary glands of adipophilin-null mice produce an amino-terminally truncated form of adipophilin that mediates milk lipid droplet formation secretion. J Lipid Res. 2008; 49:206-216. Evidence of the presence of an alternate translational start site in the adipophilin sequence. [PubMed: 17921437]

86. McManaman JL, Zabaronick W, Schaack J, Orlicky DJ. Lipid droplet targeting domains of adipophilin. J Lipid Res. 2003; 44:668-673. [PubMed: 12562852]

87. Targett-Adams P, Chambers D, Gledhill S, et al. Live cell analysis targeting of the lipid dropletbinding adipocyte differentiation-related protein. J Biol Chem. 2003; 278:15998-16007. [PubMed: 12591929]

88. Than NG, Sumegi B, Bellyei S, et al. Lipid droplet milk lipid globule membrane associated placental protein 17b (PP17b) is involved in apoptotic differentiation processes of human epithelial cervical carcinoma cells. Eur J Biochem. 2003; 270:1176-1188. [PubMed: 12631276]

89. Robenek H, Hofnagel O, Buers I, et al. Butyrophilin controls milk fat globule secretion. Proc Natl Acad Sci USA. 2006; 103:10385-10390. [PubMed: 16801554] 


\section{Executive summary}

\section{Health importance of milk lipids}

Triglycerides are major constituents of the milk of most mammals, providing a large percentage of calories needed for neonatal growth, a mechanism of transfer of lipid soluble vitamins to neonates and a source essential fatty acids needed for membrane synthesis and formation of bioactive lipid signaling molecules.

- Milk lipids are a critical source of arachidonic and docosahexaenoic acids needed for neonatal brain and retinal development.

\section{Milk lipid production \& mammary gland differentiation}

- The lactating mammary gland may be among the most active triglyceride synthesizing organs in the body.

- Triglyceride synthesis is a differentiated property of milk-secreting cells and develops as part of the program of lipogenesis that is induced during differentiation of the mammary gland into a secretory organ.

\section{Milk lipid biogenesis}

- Milk lipids are derived by secretion of cytoplasmic assemblies of triglyceride droplets surrounded by a phospholipid monolayer and surface-associated proteins called cytoplasmic lipid droplets (CLDs).

- CLDs are generated at the endoplasmic reticulum by a poorly understood mechanism.

\section{Triglyceride synthesis}

- DGAT1 is specifically required for triglyceride synthesis by milk-secreting cells.

- Protein kinase B (AKT1) is a critical regulator of triglyceride synthesis in milk-secreting cells through its actions on glucose uptake and expression of genes involved in de novo fatty acid synthesis.

- Spot 14 and Agpat-6 also play critical roles in regulating triglyceride synthesis by milk-secreting cells and are required for milk lipid production.

\section{Triglyceride stabilization}

- Adipophilin, a lipid droplet-associated protein that promotes CLD accumulation by inhibiting triglyceride lipolysis, is selectively induced in differentiating milk secreting cells of mice at the time of initial CLD accumulation.

Adipophilin is an abundantly expressed protein in the lactating mammary gland and its levels closely correlate with CLD accumulation. 


Immunofluorescence studies have linked adipophilin with xanthine
oxidoreductase and butyrophilin, two proteins known to be required for milk
lipid secretion, at sites of CLD secretion on the apical membrane.




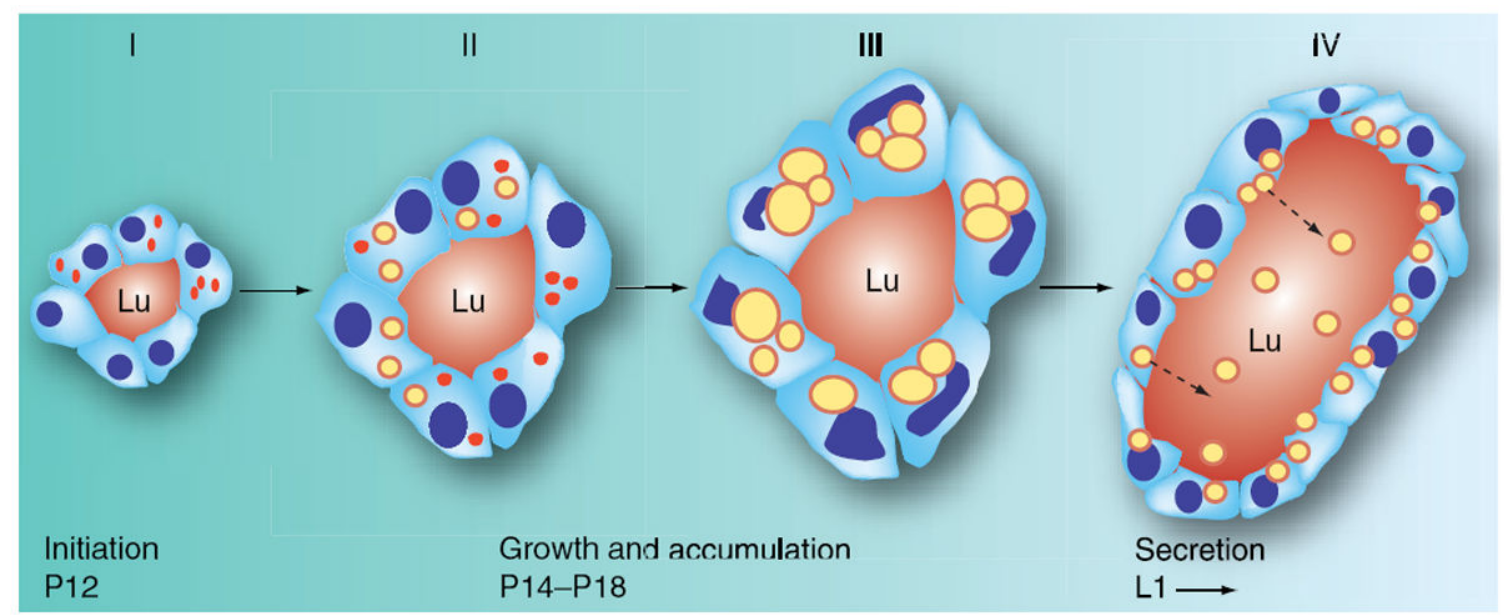

Figure 1. Lipid accumulation in differentiating milk-secreting cells occurs in phases The developmental progression of cytoplasmic lipid droplets (CLDs) and their accumulation in milk-secreting cells of differentiating mammary glands are shown in cross-sectional diagrams of alveoli. Small ( $<1 \mu \mathrm{m}$ in diameter) CLDs coated with adipophilin (indicated by red dots) are sporadically observed in milk-secreting cells at the beginning of secretory differentiation (phase I), which in mice typically begins at approximately pregnancy day 12 (P12). Between P12 and P14 (phase II) adipophilin CLDs undergo modest increases in size and number in some, but not all, milk-secreting cells. Some CLDs are now large enough that a neutral lipid core (indicated by a yellow sphere) can be seen to be surrounded by adipophilin (shown as a red annulus). Starting at P14 and progressing through P18 (typically the day before parturition) CLDs undergo sharp increases in size and number in all milksecreting cells. In milk-secreting cells of outbred CD1 mice on the day before parturition, CLDs completely fill the cytoplasm and many exceed $10 \mu \mathrm{m}$ in diameter (phase III). Following parturition and the onset of milk secretion (phase IV), CLD size and number decrease dramatically and they become enriched at the apical border of the cell and are found and secreted in the alveolar lumen. Nuclei are indicated by blue ovals, dotted arrows indicate secretion of CLDs.

Lu: Lumen. 

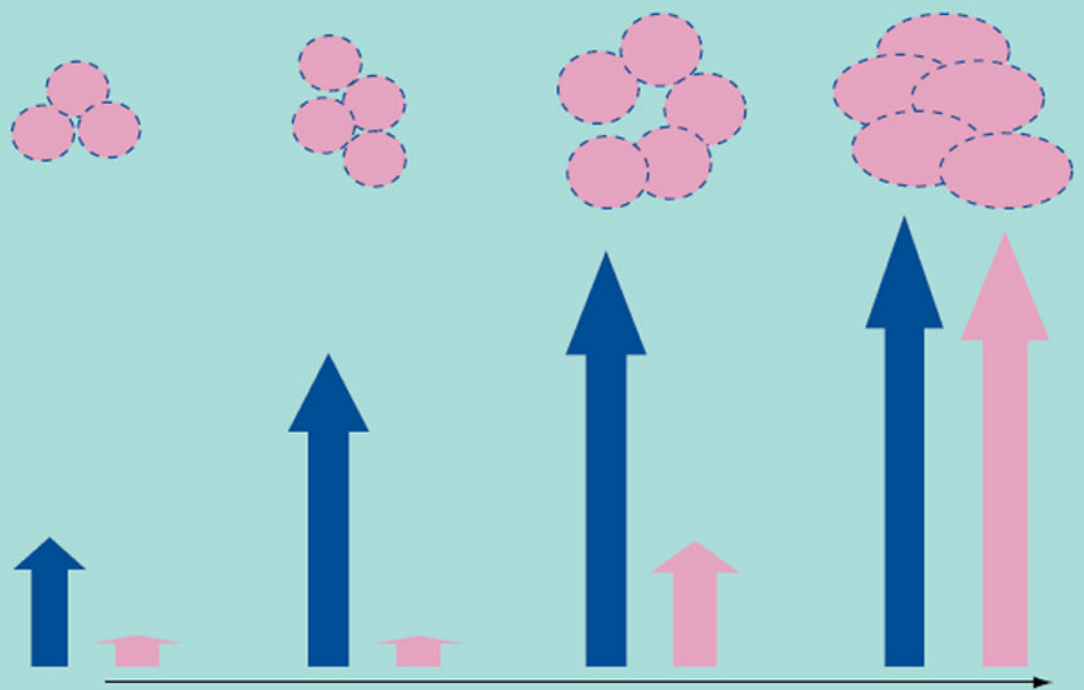

P12

P14

\section{P16}

P18

Secretory differentiation

TAG stabilization

TAG synthesis

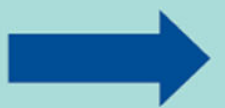

Adipophilin expression
TAG synthesis

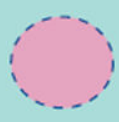

CLD

Figure 2. Bipartite model of lipogenesis in differentiating milk-secreting cells

Lipogenesis in differentiating milk-secreting cells is proposed to occur in two independently regulated and temporally distinct phases. The first phase is initiated by increased expression of adipophilin (large vertical blue arrows), and possible other molecules that impair triglyceride lipolysis, at the beginning of secretory differentiation. Increased expression of these molecules stabilizes formation of triglycerides that are synthesized at a basal rate resulting in modest increases in the size and number of CLDs (shown as a pink sphere indicating the triglyceride core and a dashed blue line to indicate surface-associated adipophilin). The second phase, induced toward the end of pregnancy, is characterized by dramatic increases in the rate of DGAT-1-dependent triglyceride synthesis (large vertical pink arrows) and further elevation in adipophilin expression. The increase in triglyceride synthesis is mediated by AKT-1-dependent increases in de novo fatty acid and glycerol synthesis and lipoprotein lipase-dependent mobilization of exogenous fatty acids from serum triglycerides.

CLD: Cytoplasmic lipid droplet; TAG: Triacylglycerol. 